\title{
Dengue virus type 4 in Niterói, Rio de Janeiro: the role of molecular techniques in laboratory diagnosis and entomological surveillance
}

\author{
Márcia Gonçalves de Castro', Rita Maria Ribeiro Nogueira², Ana Maria Bispo de Filippis², \\ Anielly Alves Ferreira', Monique da Rocha Queiroz Lima², Nieli Rodrigues da Costa Faria², \\ Fernanda de Bruycker Nogueira², Jaqueline Bastos Santos Simões², Priscila Conrado Guerra Nunes ${ }^{2}$, \\ Simone Alves Sampaioº ${ }^{2}$ Ricardo Lourenço-de-Oliveira', Flávia Barreto dos Santos ${ }^{2}+$
}

${ }^{1}$ Laboratório de Trasmissores de Hematozoários ²Laboratório de Flavivírus, Instituto Oswaldo Cruz-Fioruz, Rio de Janeiro, RJ, Brasil

In Niterói, state of Rio de Janeiro, dengue virus type 4 (DENV-4) was isolated for the first time in March 2011. We analysed the laboratory findings of the first cases and evaluated the use of molecular techniques for the detection of DENV-4 in Aedes aegypti that were field-caught. Conventional reverse transcriptase-polymerase chain reaction (RT-PCR) and Simplexa ${ }^{\mathrm{TM}}$ Dengue real-time RT-PCR confirmed DENV-4 infection in all cases. Additionally, DENV4 was confirmed in a female Ae. aegypti with $1.08 \times 10^{3} \mathrm{copies} / \mathrm{mL}$ of virus, as determined by quantitative real-time RT-PCR. This is the first time the Simplexa ${ }^{\mathrm{TM}}$ Dengue real-time assay has been used for the classification of cases of infection and for entomological investigations. The use of these molecular techniques was shown to be important for the surveillance of dengue in humans and vectors.

Key words: dengue virus type 4 - Aedes aegypti - RT-PCR - real-time RT-PCR - Simplexa ${ }^{\mathrm{TM}}$ Dengue real-time RT-PCR

Dengue is widespread in the tropical and sub-tropical areas of Asia, Africa and the Americas and the transmission of the virus is primarily associated with Aedes aegypti. In Brazil, a dengue outbreak that was caused by dengue virus (DENV) type 1 and DENV-4 was reported in 1981-1982 in a city in the Amazon Region (Osanai et al. 1983). However, it was only after DENV-1 was introduced in Rio de Janeiro (RJ) in 1986 (Schatzmayr et al. 1986) that the disease became a nationwide public health problem. Additionally, a virological and entomological program was established to monitor DENV in human sera and vectors in 1986 (Nogueira et al. 1988, 1999, Lourenço-de-Oliveira et al. 2002). RJ has assumed an important role in the epidemiology of dengue, with the first case of DENV-2 identified in 1990 (Nogueira et al. 1993) and the first case of DENV-3 identified in 2000 (Nogueira et al. 2001).

DENV-4 was reintroduced into Brazil in 2010 in the municipalities of Boa Vista and Canta, state of Roraima (RR) (Temporão et al. 2011). The virus then spread to the different regions of Brazil. Cases of infection have been identified in northern, northeastern and southeastern Brazil (MS/SVS 2011). Sequencing of the viral isolate genomes revealed that the DENV-4 Brazilian strains belonged to genotype II (de Sousa et al. 2011). In RJ, the first DENV-4 cases that were detected occurred in the Cafubá neighbourhood. Cafubá is located in the oceanic region of the municipality of Niterói which is located in the metropolitan region of RJ, Brazil (Nogueira \& Eppinghaus 2011).

Financial support: CNPq, CAPES, FIOCRUZ, FIOCRUZ/PAPES $\mathrm{V}$, FAPERJ

+ Corresponding author: flaviab@ioc.fiocruz.br

Received 27 January 2012

Accepted 15 May 2012
The entomological surveillance of DENV in adult and immature mosquito stages is an important tool for the early prediction of dengue epidemics. Additionally, the virological surveillance of field-caught dengue vectors using molecular techniques, such as conventional reverse transcriptase-polymerase chain reaction (RTPCR), has been useful for the rapid detection of dengue outbreaks in endemic regions and/or for the detection of the introduction of novel DENV variants (Chow et al. 1998, Pinheiro et al. 2005, Mendez et al. 2006, Chen et al. 2010, Guedes et al. 2010).

In this study, we aimed to characterise the first DENV4 cases and demonstrate the role of rapid molecular techniques, such as conventional RT-PCR and real-time RT-PCR, in the entomological surveillance of the newly introduced DENV-4 variant in vector populations from Niterói after it was isolated from humans. Furthermore, we evaluated a real-time PCR commercial kit that has recently become available for the detection and typing of DENV in serum samples and mosquito macerates.

Human serum samples were obtained during a surveillance program of the Laboratory of Flavivirus, Oswaldo Cruz Institute, Oswaldo Cruz Foundation (Fiocruz), RJ. This program was an on-going project that was approved by the Fiocruz Ethical Committee in Research (CEP 274/05, resolution CSN196/96), Ministry of Health.

The investigation of DENV-4 cases was performed during the RJ DENV-1 epidemic in 2011. The first two confirmed cases were two sisters who lived in the Cafubá neighbourhood of Niterói. Both experienced an onset of symptoms on March 62011 (Nogueira \& Eppinghaus 2011). We investigated nine other suspected cases of individuals who experienced an onset of symptoms from March 23 2011-April 112011 and who lived in Cafubá, São Francisco, São Domingos and Engenho do Mato (Fig. 1A). 


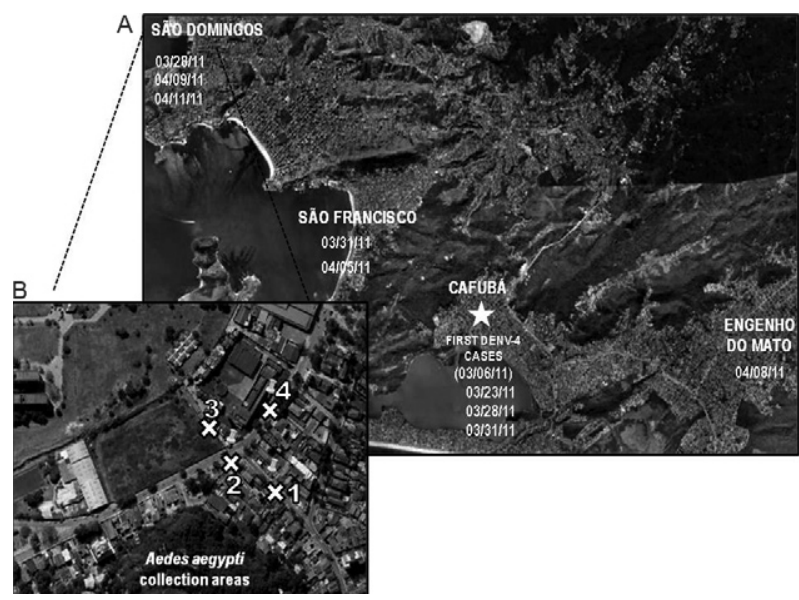

Fig. 1: dengue virus type 4 (DENV-4) introduction in Niterói, state of Rio de Janeiro, Brazil, 2011. A: Niterói neighbourhoods with DENV4 confirmed cases. Dates shown are DENV-4 confirmed cases in the different neighbourhoods; B: entomological surveillance in the São Domingos neighbourhood. White crosses represent the four collection sites within an area with confirmed DENV-4.

Ae. aegypti adult mosquitoes were collected at nine residential and non-residential sites (São Domingos) where DENV-4 human cases had been confirmed. The collection of the mosquitoes was performed at four sites (Fig. 1B) on May 4 2011, using battery-operated aspirators. Mosquitoes were anaesthetised at $4^{\circ} \mathrm{C}$, identified, sexed and stored in liquid nitrogen on the same day of collection. Seventy-two Ae. aegypti (33 females and 39 males) adult mosquitoes were collected. Of these mosquitoes, 47 (18 females and 29 males) were collected from a single site in a village-like residential area (site \#1) that was comprised of six houses. Ae. aegypti were individually macerated in $1 \mathrm{~mL}$ of Leibovitz L-15 medium (Sigma) with antibiotics (penicillin-streptomycin, 10,000 units; Invitrogen) and centrifuged (6,000 rpm at $4^{\circ} \mathrm{C}$ for $\left.30 \mathrm{~min}\right)$. The supernatant was then transferred to an Eppendorf tube that contained $100 \mathrm{~mL}$ of streptomycin/fungizone and penicillin. The tube was kept in an ice bath for $1 \mathrm{~h}$ and centrifuged $\left(3,000 \mathrm{rpm}\right.$ at $4^{\circ} \mathrm{C}$ for $15 \mathrm{~min})$. The supernatant was then transferred to an Eppendorf tube that contained $0.3 \mathrm{~mL}$ of foetal calf serum (Invitrogen) and frozen $\left(-70^{\circ} \mathrm{C}\right)$.

Virus isolation was performed by inoculating the C6/36 Aedes albopictus cell line (Igarashi 1978) and the viral isolates were identified by an indirect fluorescent antibody test using serotype-specific monoclonal antibodies (Gubler et al. 1984). Infected supernatant was clarified by centrifugation and the virus stocks were stored in $1-\mathrm{mL}$ aliquots at $-70^{\circ} \mathrm{C}$ until use.

Viral RNA was directly extracted from mosquito macerates using the QIAamp Viral RNA Mini kit (Qiagen) according to the manufacturer's instructions. The RNA was stored at $-70^{\circ} \mathrm{C}$ for DENV detection and genotyping.

RT-PCR for the detection and genotyping of DENV was performed as described previously (Lanciotti et al. 1992). DNA products of a size unique to DENV-4 (392 bp) were amplified and then analysed by agarose gel electrophoresis and ethidium bromide staining.
For the quantification of the virus, the RNA that was isolated from the individually macerated Ae. aegypti mosquitoes was subjected to a quantitative realtime RT-PCR according to the protocol described by Drosten et al. (2002).

Simplexa ${ }^{\mathrm{TM}}$ Dengue real-time RT-PCR - For the qualitative detection and typing of the viral isolates, the RNA from individually macerated Ae. aegypti mosquitoes was subjected to the Simplexa ${ }^{\mathrm{TM}}$ Dengue real-time RT-PCR assay (Focus Diagnostics, Cypress, CA) according to the manufacturer's protocol. The assay uses the 3M Integrated Cycler instrument for the in vitro detection and genotyping of DENV-1 through DENV-4. The assay is based on a real-time RT-PCR that detects DENV-1 and DENV4 in one reaction and detects DENV-2 and DENV-3 in a separate reaction. The assay uses bi-functional fluorescent primer-probes and reverse primers for the following specific regions of DENV: DENV-1 (NS5 gene), DENV-2 (NS3 gene), DENV-3 (NS5 gene) and DENV-4 (capsid gene). An internal RNA control is used to monitor the efficiency of the extraction process and to detect RT-PCR inhibition. In real-time RT-PCR, a positive reaction is detected by the accumulation of a fluorescent signal. The cycle threshold $(\mathrm{Ct})$ is defined as the number of cycles that are required for the fluorescent signal to cross a particular threshold exceeding the background level. $\mathrm{Ct}$ values are inversely proportional to the amount of target nucleic acid present in the sample. Therefore, the lower $\mathrm{Ct}$ value, the greater the amount of target nucleic acid that is present in the sample. The Simplexa ${ }^{\mathrm{TM}}$ Dengue real-time RT-PCR assay stipulates 40 cycles of amplification. The Simplexa ${ }^{\mathrm{TM}}$ Dengue kits from Focus Diagnostics were kindly provided for the evaluation. The evaluation was performed for research purposes only and the authors have no competing financial interests.

Anti-dengue $\operatorname{IgM}$ antibodies in human serum were measured using the commercially available Panbio Dengue IgM capture ELISA. The results were classified as positive, negative or equivocal according to the manufacturer's instructions.

For the NS1 antigen capture, two commercial kits were used for the analysis of human serum and macerates. The Platelia ${ }^{\mathrm{TM}}$ Dengue NS1 Ag ELISA (Biorad Laboratories, Marnes-La-Coquette, France) is a onestep, sandwich format microplate enzyme immunoassay that is used to detect the DENV NS1 antigen in human serum or plasma. The Dengue NS1 Ag STRIP (Biorad Laboratories, Marnes-La-Coquette, France) is an immunochromatographic test for the rapid detection of the NS1 antigen. This assay was performed according to the manufacturer's protocol.

During March and April 2011, a total of 11 DENV-4 cases were confirmed using the following routine laboratory diagnostic techniques: MAC-ELISA, NS1 capture ELISA and rapid test, virus isolation and conventional RT-PCR. Two of the first cases were previously analysed, both consisting of individuals who experienced an onset of symptoms on March 62011 (Nogueira \& Eppinghaus 2011). Three of the other cases occurred in the same neighbourhood as the first cases (Cafubá), three cases occurred in São Domingos, two in São Francisco 
and one occurred in Engenho do Mato (Fig. 1A). The age of the patients ranged from 14-46 years (mean \pm 24.7 years). Six patients were male and three were female. All patients had acute infections (up to 4 days of infection) and two of the nine patients $(22.2 \%)$ were positive by MAC-ELISA. The isolation of virus was possible in five out of nine patients (55.5\%) and all patients were positive by conventional RT-PCR. Four patients $(44.4 \%)$ were positive when analysed by both the NS1 capture ELISA and the NS1 Ag Strip test. We further analysed all cases using the Simplexa ${ }^{\mathrm{TM}}$ Dengue real-time RT-PCR assay and all of the cases (9/9) were confirmed as DENV-4 using this method (Table). Ct values that were obtained from the DENV-4 human samples ranged from 16.8-35.1 (mean \pm 25.0$)$ (Fig. 2).

Because of the establishment of a sentinel network for DENV surveillance, which includes blood collections from febrile cases for virus detection, in 1986 in Niterói, it was possible to detect the introduction of DENV-2 and DENV-4 into the human population early, in 1990 and 2011, respectively (Nogueira et al. 1990, Nogueira \& Epppinhaus 2011). Immediately after DENV-4 was isolated, an intensive study was conducted to monitor the distribution of the virus. Nine other DENV-4 cases from the neighbourhoods of Cafubá, São Francisco, São Domingos and Engenho do Mato were confirmed by laboratory analysis (Fig. 1A).

The development of conventional RT-PCR and realtime RT-PCR techniques has significantly reduced the processing time required to permit the detection of both the virus in the early stages of the infection in humans and its transmission by viral vectors. The DENV-4 cases that were investigated in this study were initially detected by conventional RT-PCR, which is established as a routine diagnostic test for all suspected acute dengue cases. Conventional RT-PCR results are usually released 24-48 $\mathrm{h}$ after samples are received in the laboratory. Additionally, for novel serotypes, all DENV-4 cases were re-tested separately using genotyping primers to confirm the new genotype. Concomitantly, cases were subjected to MAC-ELISA, NS1 ELISA and virus isolation. Because the cases studied consisted of patients in the acute phase of disease, MAC-ELISA was able to con- firm only two out of nine cases. Samples were obtained from both of these patients within four days after the onset of symptoms. Samples from all of the other cases were acquired within the first and second days after the onset of symptoms. The most common technique used to serologically diagnose dengue is still based on the detection of anti-DENV IgM using MAC-ELISA (Huang et al. 2001). However, one of the limitations of this method is that there are variations in the detection rate during the acute phase of disease.

A previous study showed that the NS1 capture ELISA has a higher detection rate during the first four days after the onset of symptoms compared with the MACELISA (Lima et al. 2010). In this study, both of the NS1 tests confirmed four out of the nine cases up until the fourth day after the onset of symptoms. During the acute phase of disease, the NS1 protein exists as a secreted and membrane-associated protein. Both forms of the protein have been demonstrated to be immunogenic (Young et al. 2000). High levels of NS1 have been demonstrated to circulate during the acute phase of dengue infection and they are found in the serum of patients with both primary and secondary DENV infections until the ninth day after the onset of symptoms (Young et al. 2000).

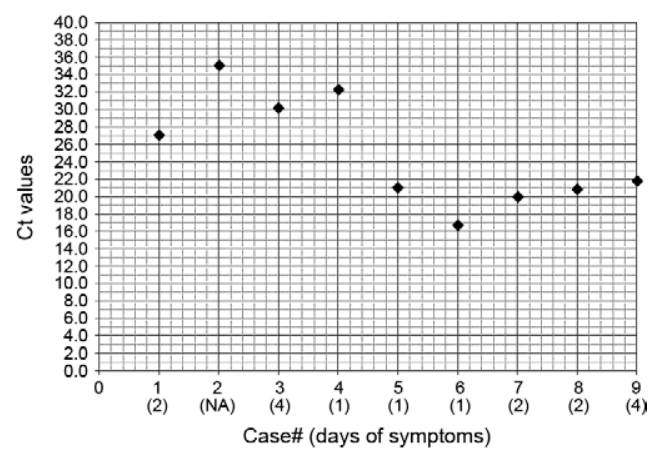

Fig. 2: Simplexa ${ }^{\mathrm{TM}}$ Dengue real-time reverse transcriptase-polymerase chain reaction amplification on dengue type 4 cases $(n=9)$ from Niterói, state of Rio de Janeiro, Brazil according to the number of days after the onset of the symptoms. Cycle threshold $(\mathrm{Ct})$ values are shown. NA: not available.

TABLE

Human dengue virus type 4 cases laboratorial investigation in Niterói, state of Rio de Janeiro, Brazil

\begin{tabular}{|c|c|c|c|c|c|c|}
\hline \multirow[b]{2}{*}{ Dengue cases } & \multicolumn{5}{|c|}{$\begin{array}{l}\text { Routine laboratorial diagnosis methodologies } \\
\text { positive/tested }\end{array}$} & \multirow{2}{*}{$\begin{array}{c}\text { Newly available } \\
\text { diagnosis methodology } \\
\text { positive/tested }\end{array}$} \\
\hline & MAC-ELISA & $\begin{array}{l}\text { Virus } \\
\text { isolation }\end{array}$ & $\begin{array}{l}\text { NS1 } \\
\text { ELISA }\end{array}$ & $\begin{array}{l}\text { NS1 Ag } \\
\text { STRIP }\end{array}$ & $\begin{array}{l}\text { Conventional } \\
\text { RT-PCR }\end{array}$ & \\
\hline Males $(n=6)$ & $2 / 6$ & $4 / 6$ & $3 / 6$ & $2 / 6$ & $6 / 6$ & $6 / 6$ \\
\hline Females $(\mathrm{n}=3)$ & $0 / 3$ & $1 / 3$ & $1 / 3$ & $2 / 3$ & $3 / 3$ & $3 / 3$ \\
\hline Total [n (\%)] & $2 / 9(22.2)$ & $5 / 9(55.5)$ & 4/9 (44.4) & 4/9 (44.4) & 9/9 (100) & 9/9 (100) \\
\hline
\end{tabular}

RT-PCR: reverse transcriptase-polymerase chain reaction. 
Despite the increased time required to produce a final result, virus isolation is still the "gold-standard" technique for the diagnosis of dengue infection. After the inoculation of $\mathrm{C} 6 / 36$ cells with the viral isolates, DENV-4 could be recovered and genotyped in five of the human cases. This technique is important because virus can be isolated from the supernatant and used for molecular epidemiologic studies by partial or complete viral genome sequencing. Sequencing and phylogenetic analysis have characterised Brazilian DENV-4 as belonging to genotype II (de Sousa et al. 2011).

All individual macerates were initially subjected to conventional RT-PCR, virus isolation and Simplexa ${ }^{\mathrm{TM}}$ Dengue real-time RT-PCR. Of the 19 total adult mosquitoes (13 males and 6 females) that were collected, DENV-4 was identified by conventional RT-PCR in a single female Ae. aegypti mosquito (1/72; $1.4 \%)$ that was captured in one of the residences (15.2). Due to the nature of the genetic material of these mosquitoes, there were many non-specific bands that were visualised on the agarose gel (Fig. 3); therefore, all of the macerates were separately retested using conventional RT-PCR with all four typing primers (TS1, TS2, TS3 and TS4). The same Ae. aegypti female, designated 15.2.4/11, was also the only mosquito that was found to be positive for DENV4 when all macerates were subjected to the Simplexa ${ }^{\mathrm{TM}}$ Dengue real-time RT-PCR assay and the mosquito was identified as having a $\mathrm{Ct}$ value of 23.5 (Fig. 4). No viruses were recovered from any of the 72 macerates when viral isolation using C6/36 cells was attempted. Realtime RT-PCR detected $1.08 \times 10^{3}$ copies $/ \mathrm{mL}$ of DENV-4 in the macerate from the single Ae. aegypti female that was naturally infected.

A single Ae. aegypti female collected at a residence in site \#1 was identified to be positive for DENV-4 infection by molecular techniques. Additionally, we performed both a NS1 capture ELISA and a NS1 Ag Strip test on all of the 47 macerates that were available from the same

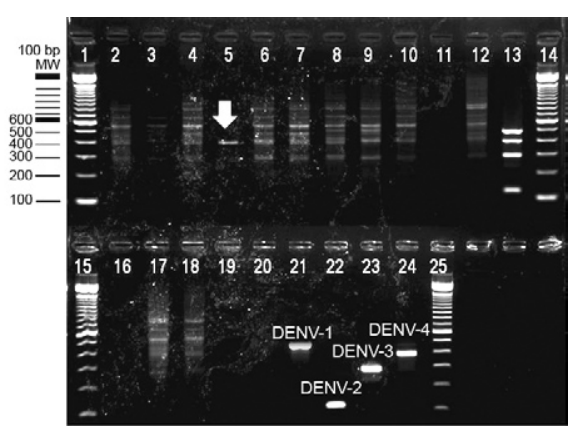

Fig. 3: conventional reverse transcriptase-polymerase chain reaction agarose gel electrophoresis analysis from Aedes aegypti adult mosquitoes, individually macerated from the entomological surveillance performed in nine residential and non-residential locations in the São Domingos neighbourhood, Niterói, state of Rio de Janeiro, Brazil in 2011. Lanes 1, 14, 15, 25: 100 bp molecular weight (Invitrogen); 2-12, 16-19: Ae. aegypti macerates; 5: dengue virus type 4 (DENV-4) positive Ae. aegypti individually macerated; 13: DENV-1-4 positive controls mix; 20: negative control (water); 21-24: DENV-1-4 positive controls, respectively. location. The same female mosquito (15.2.4/11) was positive by both of the NS1 tests. Interestingly, both tests also detected NS1 in a macerate from an Ae. aegpypti male mosquito (15.2.3). The use of the NS1 antigen capture kit for the detection of DENV antigens from Ae. aegypti mosquitoes has recently been demonstrated (Tan et al. 2011). However, none of the other techniques that were available could confirm infection or verify the infecting serotype. The transovarial transmission of DENV, which occurs when the virus is transmitted to the progeny of an infected female, has been reported previously (Khin \& Khin 1983, Joshi et al. 2002, Le Goff et al. 2011).

DENV detection rates from Aedes mosquitoes by RT-PCR may vary depending on the geographical location, epidemiological background or the vector population. In Taiwan, only $0.2 \%$ of Ae. aegypti females that were analysed were positive for DENV (Chen et al. 2010). However, it has been shown that $16.1 \%$ of the Ae. aegypti females that were collected from Mexican schools were infected with DENV (García-Rejón et al. 2011). In Brazil, previous studies showed that $17 \%$ of the Ae. aegypti mosquitoes were infected in a DENV-3 surveillance program that was initiated during an epidemic in the city of Manaus, located in the northern region of Brazil (Pinheiro et al. 2005). Conversely, only $0.1 \%$ of adult mosquitoes were found to be infected with DENV3 in an entomological surveillance study performed in $\mathrm{RJ}$ during the inter-epidemic year of 2006 (unpublished observations). In Recife, located in northeastern Brazil, $10 \%$ of the tested pools were infected and, despite the

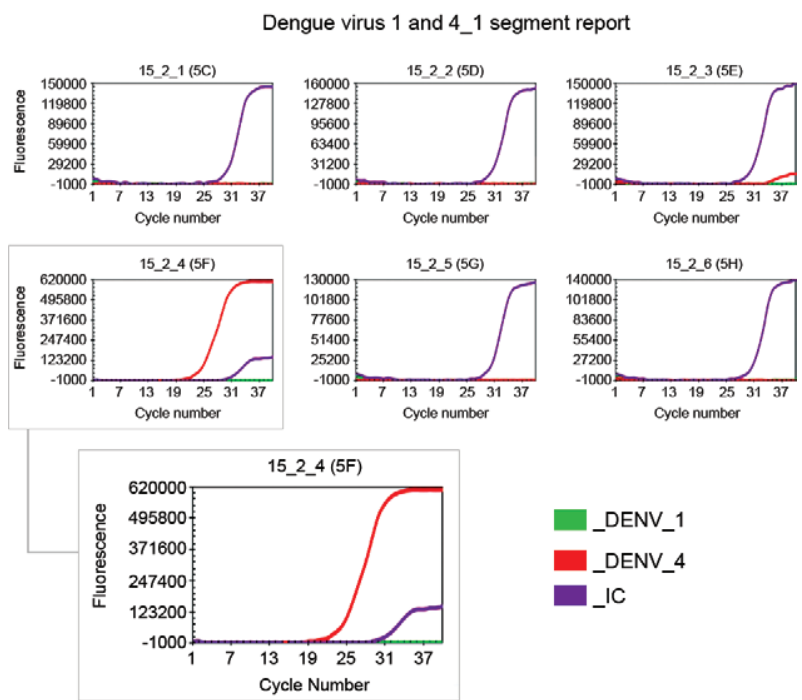

Fig. 4: Simplexa ${ }^{\mathrm{TM}}$ Dengue real-time reverse transcriptase-polymerase chain reaction amplification on Aedes aegypti mosquitoes collected in the neighbourhood of São Domingos, Niterói, state of Rio de Janeiro, Brazil and individually macerated. Experiment report sheet after reaction. Samples 5C-E, G, H: negative Ae. aegypti macerates samples \#15.4.1/11, \#15.4.2/11, \#15.4.3/11, \#15.4.5/11 and \#15.4.6/11, respectively; 5F: Ae. aegypti female \#15.2.4/11 positive for dengue virus type 4 (DENV-4) at a cycle threshold of 23.5; red line: DENV-4 probe fluorophore CFR610; purple line: internal control (IC); green line: probe fluorophore Q670. 
predominance of DENV-3 in human cases of dengue infection, both DENV-2 and DENV-1 were also detected in mosquitoes (Guedes et al. 2010).

During an entomological surveillance program performed in RJ by our group in 2001, DENV-1 was also detected in Ae. aegypti mosquitoes when the presence of DENV-3 was being investigated. Likewise, DENV-1 was also detected during a DENV-4 surveillance study in RR in 2010 (MG de Castro et al., unpublished observations). It has been suggested that a predominant serotype may persist for one or two years until it is replaced by a new serotype (Chow et al. 1998). In the present study, infection with DENV-4 in humans and mosquitoes was confirmed during an explosive DENV-1 epidemic in RJ, as well as in other Brazilian states. During this epidemic, approximately $87 \%$ of the confirmed dengue cases that were reported in 2011 were confirmed to be DENV-1 infections (MS/SVS 2011).

Real-time RT-PCR methods have been established as a more rapid and sensitive technique for the detection and quantification of DENV in clinical samples (Drosten et al. 2002, Lai et al. 2007). In this study, we used quantitative real-time RT-PCR to quantify the DENV-4 viral titre $\left(1.08 \times 10^{3}\right.$ copies $\left./ \mathrm{mL}\right)$ from a single $A e$. aegypti female mosquito that was naturally infected and individually macerated.

We also evaluated, for the first time, the effectiveness of the Simplexa ${ }^{\mathrm{TM}}$ Dengue real-time RT-PCR kit for the detection and genotyping of DENV in both human cases and Ae. aegypti samples. All of the DENV-4 human cases that were analysed in this study were confirmed using a commercial real-time RT-PCR kit. The Ct values that were observed ranged from 16.8-35.1 (mean \pm 25.0$)$. The $\mathrm{Ct}$ values in a real-time PCR assay are inversely proportional to the amount of target nucleic acid that is present in the sample. Because all of the samples were obtained during the acute phase of disease (2 samples within 4 days of the onset of symptoms, 3 samples within 2 days of the onset of symptoms, 3 samples within 1 day of the onset of symptoms and 1 sample in which the timing was unknown), high viraemia levels would be expected, resulting in lower $\mathrm{Ct}$ values (Fig. 2). From all of the Ae. aegypti macerates that were subjected to the Simplexa $^{\mathrm{TM}}$ Dengue real-time RT-PCR analysis, only female 15.2.4/11 was positive for DENV-4 and was observed to have a low $\mathrm{Ct}$ value (23.5). This suggests that there was a high viral load in the single female (Fig. 3).

Despite the confirmation of DENV-4 cases in RJ, a major DENV-1 epidemic was established at the same time. In December 2011, a new DENV-4 case was identified in Niterói and confirmed by the laboratory methods that were available. This case was identified eight months after the first cases were confirmed. Therefore, our overall results with regard to the laboratory diagnosis and entomological surveillance of dengue using molecular techniques, such as conventional RT-PCR and real-time RT-PCR, show that these approaches are fast, reliable, sensitive and specific for dengue serotype surveillance. Furthermore, these techniques were found to still be effective when a new serotype is introduced or when a serotype re-emerges during a dengue epidemic of a different serotype.

\section{ACKNOWLEDGEMENTS}

To Mauro Menezes Muniz, Roberto Costa Peres, Reginaldo Rego, Marcelo Celestino dos Santos, Renato Carvalho de Andrade, Wellington C Silva, Eliane Saraiva Machado de Araújo, Bianca de Santis and José da Costa Farias Filho, for technical assistance, and to Focus Diagnostics, represented by Medivax, Brazil, for providing the Simplexa Dengue kits for evaluation.

\section{REFERENCES}

Chen CF, Shu PY, Teng HJ, Su CL, Wu JW, Wang JH, Lin TH, Huang $\mathrm{JH}, \mathrm{Wu} \mathrm{H}$ 2010. Screening of dengue virus in field-caught Aedes aegypti and Aedes albopictus (Diptera: Culicidae) by one-step SYBR green-based reverse transcriptase-polymerase chain reaction assay during 2004-2007 in southern Taiwan. Vector Borne Zoonotic Dis 10: 1017-1025.

Chow VT, Chan YC, Yong R, Lee KM, Lim LK, Chung YK, LamPhua SG, Tan BT 1998. Monitoring of dengue viruses in fieldcaught Aedes aegypti and Aedes albopictus mosquitoes by a type-specific polymerase chain reaction and cycle sequencing. Am J Trop Med Hyg 58: 578-586.

de Souza RP, Rocco IM, Maeda AY, Spenassatto C, Bisordi I, Suzuki A, Silveira VR, Silva SJ, Azevedo RM, Tolentino FM, Assis JC, Bassi MG, Dambrós BP, Tumioto GL, Gregianini TS, Souza LT, Timenetsky M do C, Santos CL 2011. Dengue virus type 4 phylogenetics in Brazil 2011: looking beyond the veil. PLoS Negl Trop Dis 5: e1439.

Drosten C, Göttig S, Schilling S, Asper M, Panning M, Schmitz H, Günther S 2002. Rapid detection and quantification of RNA of Ebola and Marburg viruses, Lassa virus, Crimean-Congo hemorrhagic fever virus, Rift Valley fever virus, dengue virus and yellow fever virus by real-time reverse transcription-PCR. J Clin Microbiol 40: 2323-2330.

García-Rejón JE, Loroño-Pino MA, Farfán-Ale JA, Flores-Flores LF, López-Uribe MP, Najera-Vazquez M del R, Nuñez-Ayala G, Beaty BJ, Eisen L 2011. Mosquito infestation and dengue virus infection in Aedes aegypti females in schools in Merida, Mexico. Am J Trop Med Hyg 84: 489-496.

Gubler DJ, Kuno G, Sather GE, Velez M, Oliver A 1984. Mosquito cell cultures and specific monoclonal antibodies in surveillance for dengue viruses. Am J Trop Med Hyg 33: 158-165.

Guedes DR, Cordeiro MT, Melo-Santos MA, Magalhaes T, Marques E, Regis L, Furtado AF, Ayres CF 2010. Patient-based dengue virus surveillance in Aedes aegypti from Recife, Brazil. J Vector Borne Dis 47: 67-75.

Huang JL, Huang JH, Shyu RH, Teng CW, Lin YL, Kuo MD, Yao CW, Shaio M 2001. High-level expression of recombinant dengue viral NS-1 protein and its potential use as a diagnostic antigen. J Med Virol 65: 553-560.

Igarashi A 1978. Isolation of a singh's Aedes albopictus cell clone sensitive to dengue and Chikungunya viruses. J Gen Virol 40: 531-544.

Joshi V, Mourya DT, Sharma RC 2002. Persistence of dengue-3 virus through transovarial passage in successive generations of Aedes aegypti mosquitoes. Am J Trop Med Hyg 67: 158-161.

Khin MM, Khin AT 1983. Transovarial transmission of dengue-2 virus by Aedes aegypti in nature. Am J Trop Med Hyg 32: 590-594.

Lai YL, Chung YK, Tan HC, Yap HF, Yap G, Ooi EE, Ng LC 2007. Cost-effective real-time reverse transcriptase-PCR (RT-PCR) to screen for dengue virus followed by rapid single-tube multiplex RT-PCR for serotyping of the virus. J Clin Microbiol 45: 935-941.

Lanciotti RS, Calisher CH, Gubler DJ, Chang GJ, Vorndam AV 1992. Rapid detection and typing of dengue viruses from clinical samples by using reverse transcriptase-polymerase chain reaction. J Clin Microbiol 30: 545-551. 
Le Goff G, Revollo J, Guerra M, Cruz M, Barja Simon Z, Roca Y, Vargas Florès J, Hervé JP 2011. Natural vertical transmission of dengue viruses by Aedes aegypti in Bolivia. Parasite 18: 277-280.

Lima M da R, Nogueira RM, Schatzmayr HG, dos Santos FB 2010. Comparison of three commercially available dengue NS1 antigen capture assays for acute diagnosis of dengue in Brazil. PLoS Negl Trop Dis 4: e738.

Lourenço-de-Oliveira R, Honório NA, Castro MG, Schatzmayr HG, Miagostovich MP, Alves JCR, Silva WC, Leite PJ, Nogueira RMR 2002. Dengue virus type 3 isolation from Aedes aegypti in the municipality of Nova Iguaçu, State of Rio de Janeiro. Mem Inst Oswaldo Cruz 97: 799-800.

Mendez F, Barreto M, Arias JF, Rengifo G, Muñoz J, Burbano ME, Parra B 2006. Human and mosquito infections by dengue viruses during and after epidemics in a dengue-endemic region of Colombia. Am J Trop Med Hyg 74: 678-683.

Nogueira RMR, Eppinghaus ALF 2011. Dengue virus type 4 arrives in the State of Rio de Janeiro: a challenge for epidemiological surveillance and control. Mem Inst Oswaldo Cruz 106: 255-256.

Nogueira RMR, Miagostovich MP, de Filippis AMB, Pereira MAS, Schatzmayr HG 2001. Dengue virus type 3 in Rio de Janeiro, Brazil. Mem Inst Oswaldo Cruz 96: 925-926.

Nogueira RMR, Miagostovich MP, Lampe E, Schatzmayr HG 1990. Isolation of dengue virus type 2 in Rio de Janeiro. Mem Inst Oswaldo Cruz 85: 253.

Nogueira RMR, Miagostovich MP, Lampe E, Souza RW, Zagne SM, Schatzmayr HG 1993. Dengue epidemic in the stage of Rio de Janeiro, Brazil, 1990-1: co-circulation of dengue 1 and dengue 2 serotypes. Epidemiol Infect 111: 163-170.

Nogueira RMR, Miagostovich MP, Schatzmayr HG, dos Santos FB, de Araújo ESM, de Filippis AMB, de Souza RV, Zagne SMO, Nicolai
C, Baran M, Teixeira Filho G 1999. Dengue in the State of Rio de Janeiro, Brazil, 1986-1998. Mem Inst Oswaldo Cruz 94: 297-304.

Nogueira RMR, Schatzmayr HG, Miagostovich MP, Farias MFDB, Farias Filho JC 1988. Virological study of a dengue type 1 epidemic at Rio de Janeiro. Mem Inst Oswaldo Cruz 83: 219-225.

Osanai CH, Travassos da Rosa AP, Tang AT, do Amaral RS, Passos AD, Tauil P 1983. Dengue outbreak in Boa Vista, Roraima. Preliminary report. Rev Inst Med Trop Sao Paulo 25: 53-54.

Pinheiro VCS, Tadei WP, Barros PMSS, Vasconcelos PFC, Cruz ACR 2005. Detection of dengue virus serotype 3 by reverse transcription-polymerase chain reaction in Aedes aegypti (Diptera, Culicidae) captured in Manaus, Amazonas. Mem Inst Oswaldo Cruz 100: 833-839.

Schatzmayr HG, Nogueira RMR, Travassos da Rosa APA 1986. An outbreak of dengue virus at Rio de Janeiro - 1986. Mem Inst Oswaldo Cruz 81: 245-246.

MS/SVS - Ministério de Saúde/Secretaria de Vigilância em Saúde 2011. Balanço dengue - Semana Epidemiológica. Available from: portal. saude.gov.br/portal/arquivos/pdf/informe_dengue_072011.pdf.

Tan CH, Wong PS, Li MZ, Vythilingam I, Ng LC 2011. Evaluation of the dengue NS1 Ag Strip ${ }^{\circledR}$ for detection of dengue virus antigen in Aedes aegypti (Diptera: Culicidae). Vector Borne Zoonotic Dis 11: 789-792.

Temporão JG, Penna GO, Carmo EH, Coelho GE, do Socorro Silva, Azevedo R, Teixeira Nunes MR, da Costa Vasconcelos PF 2011. Dengue virus serotype 4, Roraima state, Brazil. Emerg Infect Dis 17: 938-940.

Young PR, Hilditch PA, Bletchly C, Halloran W 2000. An antigen capture enzyme-linked immunosorbent assay reveals high levels of the dengue virus protein NS1 in the sera of infected patients. J Clin Microbiol 38: 1053-1057. 